\title{
The interaction of syntactical structure and learning instructions
}

WILLIAM EPSTEIN AND MARTIN ARLINSKY

UNIVERSITY OF KANSAS

\begin{abstract}
The interaction of syntactical structure and learning instructions was investigated. When the method of complete presentation was used the superiority of syntactical over unsyntactical material was greater for intentional as compared with incidental learners.
\end{abstract}

\section{Introduetion}

This is a report of a preliminary investigation of the interaction of syntactical structure and learning instructions in influencing the free recall of sentence-like material. Postman \& Adams' (1960) findings suggest the liklihood of this interaction. They found that the effects of variations of order of approximation on free recall was greater for Ss who received intentional learning instructions than for those who received incidental learning instructions. A similar interaction was expected in this study. The superiority of syntactical over unsyntactical material (Epstein, 1961, 1962) should be greater for intentional than for incidental learners. To examine the generality of this interaction two additional variables were included: length of the sentence and mode of presentation.

\section{General Plan}

The experiment was a $2 \times 2 \times 2 \times 2$ randomized blocks design. The following were the four factors: structure, syntactical vs. unsyntactical; learning instruction s, intentional vs. incidental; length, 11-word vs. 22-word; presentation, complete vs. serial. Subjects

The Ss were 128 English-speaking students of General Psychology with no previous experience as experimental Ss. There were 8 blocks of 16 Ss who were assigned to conditions according to a table of random numbers. Material

Table 1 shows the two 11-word and 22-word series which were used. All four series are sententially meaningless, and of a low order of approximation to the statistical structure of English. However, two of these
TABLE I. LEARNING MATERIAL

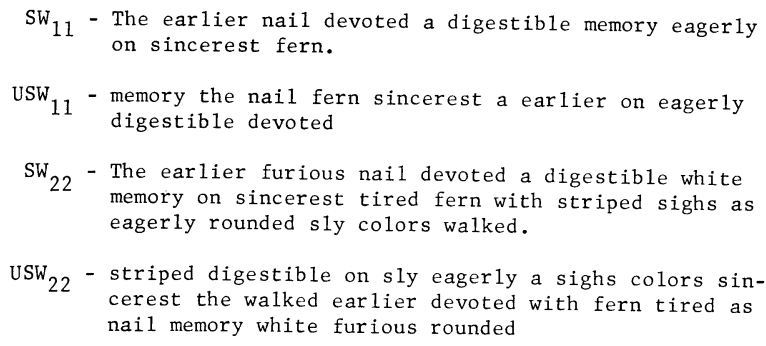

$\mathrm{USW}_{22}$ - striped digestible on sly eagerly a sighs colors sincerest the walked earlier devoted with fern tired as nail memory white furious rounded

$\left(\mathrm{SW}_{11}\right.$ and $\left.\mathrm{SW}_{22}\right)$ are consonant with the syntactical structure of English and two $\left(\mathrm{USW}_{11}\right.$ and $\left.\mathrm{USW}_{22}\right)$ are not.

\section{Procedure}

The intentional and incidental learning instructions were similar to those used by Postman \& Adams (1960). Following the instructions each $\mathrm{S}$ was given one learning trial. When complete presentation was used the entire series was presented on a card in the conventional horizontal arrangement of English writing. The exposure was $22 \mathrm{sec}$. for the 11-word series and $44 \mathrm{sec}$. for the 22-word series. When the material was presented serially the series was exposed item by item in a memory drum at a $2-$ sec. rate. ${ }^{1}$ Thirty sec. following the termination of the learning exposure $\mathrm{S}$ was asked to reproduce the material in writing. The recall instructions solicited free recall of the items in the order in which they came to mind. Two min. were allowed for the recall test.

\section{Results}

Table 2 shows the mean number of correct recalls for the 16 experimental conditions. Table 3 presents a summary of the analysis of variance of these data. All the main effects were significant. Table 3 shows that higher recall scores were associated with the structured material, 22-word series, complete presentation and intentional learning instructions.

\begin{tabular}{|c|c|c|c|c|c|}
\hline \multirow[b]{2}{*}{ Material } & \multicolumn{2}{|c|}{ Intentional } & \multicolumn{2}{|c|}{ Incidental } & \multirow[b]{2}{*}{ Overa11 } \\
\hline & Complete & $\underline{\text { Serial }}$ & Complete & $\underline{\text { Serial }}$ & \\
\hline $\mathrm{SW}_{11}$ & 7.88 & 5.62 & 4.75 & 5.00 & 5.94 \\
\hline $\mathrm{USW}_{11}$ & 5.87 & 5.87 & 5.25 & 4.50 & 5.36 \\
\hline $\mathrm{SW}_{22}$ & 11.00 & 7.75 & 5.25 & 6.13 & 7.53 \\
\hline $\mathrm{USW}_{22}$ & 7.13 & 6.00 & 4.13 & 5.50 & 5.69 \\
\hline Overall & 7.97 & 6.20 & 4.84 & 5.50 & -- \\
\hline
\end{tabular}


Of greater interest are the interaction effects. Most relevant to the main concerns of the present study are the significant interactions $(A B, A D, A C D)$ involving the structure factor. The nature of these interactions may be discerned in Table 2. Concerning the $A B$ interaction it may be seen that the superiority of syntactical over unsyntactical material is greater for the 22-word series than for the 11-word series. This finding is compatible with Miller \& Selfridge's (1953) finding that the facilitation of learning produced by increasing the order of approximation of a message is greater with longer than with shorter messages.

The presence of a significant interaction between syntax and learning instructions $(\mathrm{AD})$ reflects the

TABLE 3. SUMMARY OF ANALYSIS OF VARIANCE OF CORRECT RECALLS

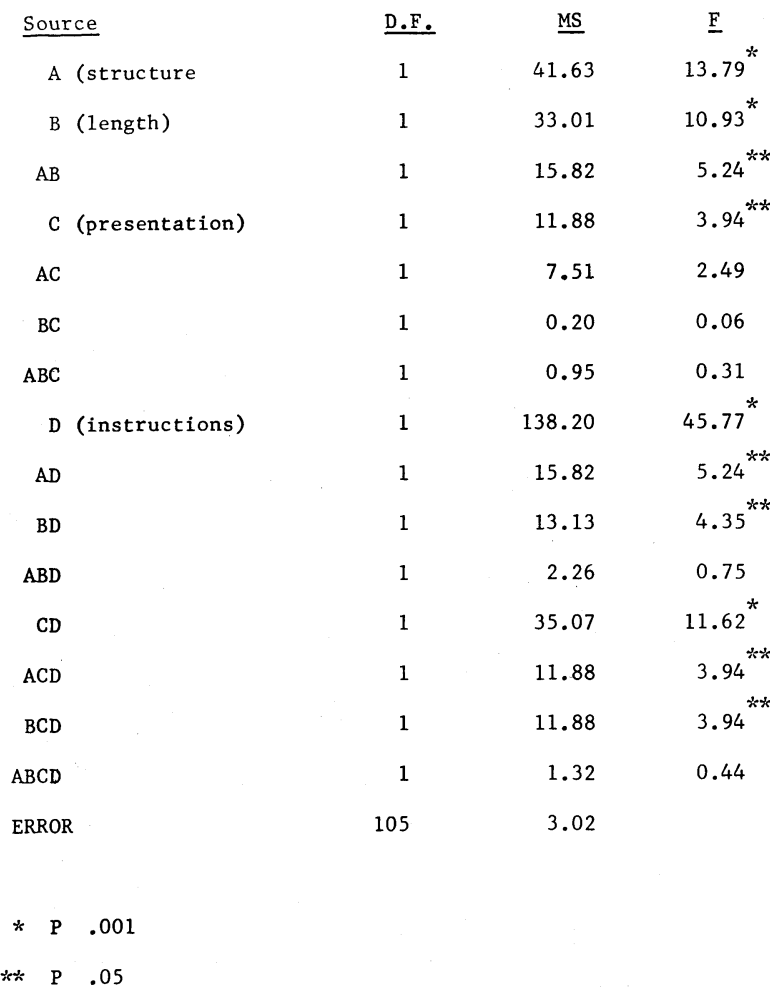

greater superiority of syntactical material under intentional learning instructions than under incidental instructions. Fractionation of the ACD interaction shows that the above interaction between syntax and instructions is confined to the conditions of complete presentation. Under this condition the difference between SW and USW was greater for the intentional learners. When serial presentation was used SW and USW did not differ with either instructional condition. This finding is consistent with Epstein's (1962) results.

\section{Diseussion}

When the material is presented by the method of complete presentation there is some evidence to indicate that the facilitative effect of syntax is enhanced by intentional learning instructions. This finding can be understood by noting that the experimental procedure, which involved only a single exposure of the material, placed a premium on prompt detection of syntactical structure. Under these conditions incidental learners, who are less motiviated to make the discriminatory responses which facilitate learning, are also less likely to detect the structural cues. For this reason incidental learners will benefit less from the presence of syntactical structure. Experimentation is currently in progress to investigate this question with a greater variety of language samples and syntactical samples and under a variety of conditions.

\section{References}

Epstein, W. The influence of syntactical structure on learning. Amer. J. Psychol., 1961, 74, 80-85.

Epstein, W. A further study of the influence of syntactical structure on learning. Amer. J. Psychol., 1962, 75, 121-126.

Miller, G. A., \& Selfridge, J. A. Verbal context and the recall of meaningful material. Amer. J. Psychol., 1953, 63, 176-185.

Postman, L., \& Adams, P. Studies of incidental learning: VIII. The effects of contextual determination. J. exp. Psychol., 1960, 59, 153-164.

\section{Note}

1. The decision was made to confound length of material with total exposure time. The alternative is to keep total exposure time constant and confound length with exposure time per item. The latter confounding seemed to introduce more problems of interpretation than the former. 